\title{
Comunicação pública e constituição de cenas de dissenso em contextos institucionais
}

Public communication and constitution of scenarios of dissent in institutional contexts

Comunicación pública y constitución de escenas de disenso en contextos institucionales

Ângela Cristina Salgueiro Marques

- Pós-doutora em Comunicação pela Université Stendhal (Grenoble III), e em Ciências Sociais pela Université Pierre-Mendès-France (Grenoble II), da França

- Doutora, mestre e graduada em Comunicação Social pela Universidade Federal de Minas Gerais (UFMG)

- Professora adjunta do Departamento de Comunicação Social da UFMG, atuando também na pós-graduação.

- Foi professora do Programa de Pós-Graduação em Comunicação da Faculdade Cásper Líbero (Facásper)

- Bolsista de Produtividade do CNPq.

- E-mail: angelasalgueiro@gmail.com 


\section{Resumo}

Este artigo tem como objetivo ressaltar as potencialidades e fragilidades de uma compreensão da comunicação pública associada a um desenho político e democrático sustentado por práticas dialógicas em redes de esferas públicas, de prestação de contas e reciprocidade, de participação cívica e política e de construção da autonomia e da cidadania. 0 ideal normativo de democracia proposto por Jürgen Habermas pauta essa concepção trazendo consigo várias qualidades, mas também muitos limites já apontados por seus críticos, sobretudo quando se trata do papel dúbio desempenhado pelos meios de comunicação na constituição de esferas públicas e do difícil exercício de parceiros de debate criarem cenas de dissenso nas quais se reconhecem como sujeitos de fala e efetivos interlocutores.

\section{PALAVRAS-CHAVE: COMUNICAÇÃO PÚBLICA •ÉTICA DO DISCURSO • CENAS DE DISSENSO•AUTONOMIA.}

\section{Abstract}

The aim of this article is to highlight the potentialities and weaknesses of an understanding of public communication associated with political and democratic models backed by dialogical practices in public sphere networks, reciprocity and accountability, civic and political participation, construction of independence and citizenship. The normative ideal of democracy presented by Jürgen Habermas bases this conception bringing with it certain qualities, but also many limitations already pointed out by his critics, particularly when concerning the questionable role played by the communication media in the creation of public spheres and also with the difficult exercise of debate partners of creating scenarios of dissent, in which partners recognize each other as citizens of speech and effective interlocutors.

\section{KEYWORDS: PUBLIC COMMUNICATION・DISCOURSE ETHICS・SCENARIOS OF DISSENT•INDEPENDENCE.}

\section{Resumen}

Este artículo tiene como objetivo destacar las potencialidades y fragilidades de una comprensión de la comunicación pública asociada a un ideal político democrático apoyado por prácticas dialógicas en redes de esferas públicas, de reciprocidad y prestación de cuentas, de participación cívica y política y de construcción de la autonomía y de la ciudadanía. El ideal normativo de democracia propuesto por Jürgen Habermas guía este concepto trayendo consigo varias cualidades, pero también muchos límites ya señalados por sus críticos, sobre todo cuando se trata del papel dubio desempeñado por los medios de comunicación en la constitución de esferas públicas y del difícil ejercicio de colegas de debate por crear escenas de disenso en las cuales se reconocen como sujetos hablantes y efectivos interlocutores. 


\section{ANO 12 • NÚMERO $22 \cdot 1^{0}$ sem. 2015 - ORGANICOM COMUNICAÇÃO PÚBLICA E CONSTITUIÇÃO DE CENAS DE DISSENSO EM CONTEXTOS INSTITUCIONAIS}

A grande multiplicidade de perspectivas e abordagens que buscam traduzir os processos comunicacionais dedicados à interlocução entre estado, governo e sociedade civil nos conduzem a refletir acerca da construção do conceito de comunicação pública como um constante exercício de configuração e reconfiguração de seus principais elementos (zémor, 1995). usualmente entendida como "processo comunicativo que se instaura entre o estado, o governo e a sociedade civil com o objetivo de se configurar como espaço de negociação entre interesses das diversas instâncias de poder da vida pública de uma nação" (Brandão, 2009, p. 31), a comunicação pública seria aquela feita por instituições públicas e privadas, pautada por ações estratégicas dirigidas a públicos específicos e justificadas em nome do interesse público e da construção da cidadania.

Assim, em sentido lato, a comunicação pública poderia abranger diferentes dimensões da comunicação governamental e da comunicação política', sem se confundir com uma comunicação estritamente midiática: propaganda política, as difusões de informação pelo governo e instituições administrativas, além do marketing político e eleitoral. ${ }^{2}$ Privilegiamse nesse escopo, a interseção entre: a) serviços básicos de publicização e circulação de informações (permitindo acesso a atos e regimentos); b) campanhas publicitárias e/ou jornalísticas para apoiar a implementação de normas ou políticas públicas que precisam de ampla informação social e de compartilhamento; c) gestão do capital simbólico acumulado pelas instituições em relação a seu território e competências; d) a relação entre as instituições e o sistema midiático (tanto para conferir visibilidade quanto para silenciar acontecimentos) (Rolando, 2011, p. 28-29).

A comunicação pública implica várias vertentes e significações, podendo-se entendê-la, basicamente, segundo essas quatro concepções básicas: comunicação estatal; comunicação da sociedade civil organizada que atua na esfera pública em defesa da coletividade; comunicação institucional dos órgãos públicos, para promoção de imagem, dos serviços e nas eleições (Kunsch, 2013, p. 6).

Estudos recentes têm apontado uma ampliação do conceito de comunicação pública (Jaramillo López, 2011; Matos, 2011; Matos e Gil, 2013a; Matos e Gil, 2013b; Duarte, 2011; Koçouski, 2013; Bueno, 2015), não só no que diz respeito ao envolvimento do setor privado ${ }^{3}$ na implementação de políticas e normas, mas também no que tange à atuação das ONGs, ao aumento da participação popular, ao surgimento de conselhos, fóruns de discussão e arenas híbridas digitais. Essas mudanças associam-se às práticas que objetivam favorecer o engajamento cívico e a participação dos cidadãos no debate de questões de interesse coletivo.

A comunicação pública é gerida por instituições, administrações públicas, empresas de serviços públicos, indivíduos que representam interesses coletivos e orientados em função do mandato conferido pelo eleitorado e da política que o rege, no sentido de diminuir a distância entre instituições e cidadãos na vida cotidiana (Rolando, 2011, p. 27).

Nesse âmbito, a comunicação pública envolve sobremaneira o interesse público, princípios democráticos e constituição de redes de interlocução. Ela seria uma forma não só de representar os mecanismos de poder (e seus discursos), mas para fazer com que a relação entre diferentes atores sociais e institucionais funcione sobre as bases de projetos efetivamente coletivos.

Consideramos a comunicação pública não apenas como a instrumentalização do poder mas, sobretudo, como o território em que muitos sujeitos (mesmo se confrontando) buscam interesses legítimos e usam a informação e a comunicação não tanto para vender algo, mas para apresentar sua identidade, sua visão e seus objetivos (Rolando, 2011, p. 26).

A comunicação pública poderia, assim, melhor "traduzir" uma intenção de instauração de processos e práticas políticas voltadas para a configuração de uma "rede, simbolicamente constituída, a partir de temas relevantes para o interesse

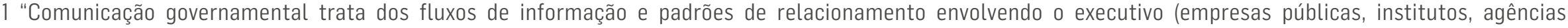

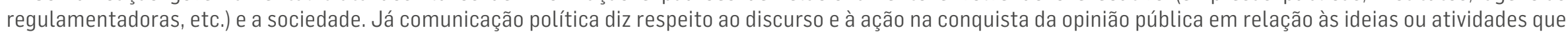

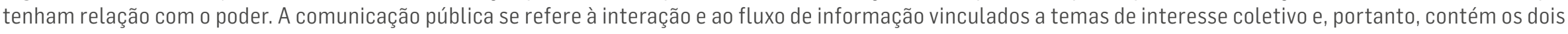
anteriores" (Duarte, 2011, p. 126).

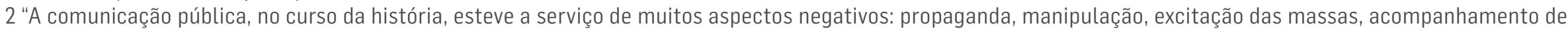
guerras e destruição do inimigo, criação de leis injustas, discriminação social e ética, poder pessoal, humilhação da democracia" (Rolando, 2011, p. 25).

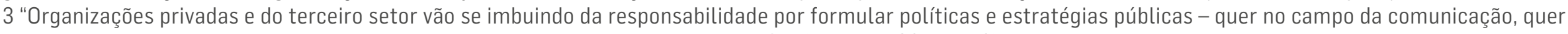
no da atitude e ação (por exemplo, no reconhecimento de segmentos sociais excluídos)" (Matos, 2011, p. 40).
} 
público, de caráter transitório ou permanente, assumidos por empresas privadas, organizações não-governamentais, instituições públicas etc." (Kunsch, 2011, p. 15). Sua função estratégica consistiria em estabelecer mediações entre atores cívicos e governo, privilegiando o diálogo, a transparência e a accountability, além de pautar-se pelo interesse coletivo. Duarte (2011, p. 132) estabelece, nesse sentido, quatro eixos da comunicação pública: a transparência e a postura ética dos agentes envolvidos; 0 acesso e a adequação da informação aos públicos envolvidos; o diálogo e as interações paritárias e simétricas; e a ouvidoria social (compreensão da opinião pública e dos segmentos que a compõem).

A comunicação pública ocupa-se da viabilização do direito social individual e coletivo à informação, à expressão, ao diálogo e à participação. Fazer comunicação pública é assumir a perspectiva cidadã na comunicação envolvendo temas de interesse coletivo, alterando seu eixo, tradicionalmente centrado no atendimento dos interesses da instituição e de seus gestores. Na comunicação pública o objetivo é o atendimento do interesse público e da sociedade, simbolizado pelo cidadão (Duarte, 2011, p. 126-127).

Depreende-se desse entendimento não só um modelo de comunicação pública, mas, sobretudo, um desenho político e democrático que sustente as práticas dialógicas, de prestação de contas e reciprocidade, de participação cívica e política e de construção da autonomia e da cidadania. Sob esse aspecto e, como veremos mais adiante, as abordagens recentes dos processos de comunicação pública têm apresentado inúmeras interfaces com modelos democráticos deliberativos, participativos e até mesmo radicais (defesa da perspectiva agonística).

De alguma forma, e tendo como apoio artigos e livros publicados recentemente sobre o tema (Matos e Gil, 2013a; Oliveira, 2013), a comunicação pública parece ser discutida, no âmbito nacional e internacional, como prática que se constitui e se estrutura através de uma rede de trocas comunicativas que configuram e articulam esferas públicas, promovendo debates ampliados e participação cívica.

\section{COMUNICAÇÃO PÚBLICA E AÇÃO COMUNICATIVA}

A perspectiva de Jürgen Habermas $(1997 ; 2006)$ sobre a constituição de esferas públicas via argumentação racional e inclusiva parece pautar a reflexão de vários autores estrangeiros e brasileiros que discutem a comunicação pública. 0 colombiano Jaramillo Lopez (2011) é um dos autores que atualmente defendem uma compreensão da comunicação pública pautada pelas noções de esfera pública, ação comunicativa e deliberação. Para ele, a comunicação pública é fruto da interface entre comunicação e política, da participação de todos os potencialmente afetados por um problema público em debates que buscam solucioná-lo e da dinâmica de justificação pública que objetiva produzir entendimentos e decisões potencialmente justos para todos 4 . Sua dinâmica requer o diálogo e a negociação recíproca em redes de trocas e justificações discursivas que dão origem a esferas públicas (Oliveira, 2013).

No âmbito nacional, destaco, sobretudo, a abordagem desenvolvida por Matos (2006; 2009), para quem a comunicação pública se delineia a partir de situações paritárias de discussão e negociação entre diferentes atores sociais.

A comunicação pública está relacionada à democratização do saber. (...) Se todos os agentes participam do debate das questões de interesse e utilidade comum, se essa participação é possível graças à existência de uma infraestrutura que materializa a esfera pública, se eles se sentem aptos e motivados a participar graças à cultura de valorização de seu papel social, se os critérios de instituição e processo do debate são claros e equitativos, então será possível preencher os requisitos mínimos para o reconhecimento da comunicação pública (Matos, 2009, p. 57).

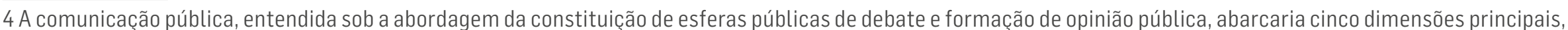

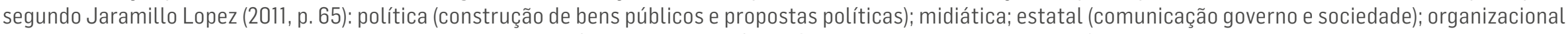
(dentro desses espaços circulam mensagens e interesses configurando uma esfera pública particular); vida social e âmbitos comunicacionais do cotidiano.
} 


\section{ANO 12 • NÚMERO $22 \cdot 1^{0}$ sem. 2015 - ORGANICOM COMUNICAÇÃO PÚBLICA E CONSTITUIÇÃO DE CENAS DE DISSENSO EM CONTEXTOS INSTITUCIONAIS}

Matos (2006; 2009; 2013) desenvolve possibilidades de interface entre a comunicação pública e a comunicação política salientando que ambas abordam o processo de comunicação instaurado em uma rede de esferas públicas que envolve 0 Estado, o governo e diferentes setores da sociedade, privilegiando debates, negociações e tomadas de decisão relativas a questões de interesse coletivo.

Os temas, assuntos e interesses envolvendo questões de poder na sociedade precisam implicar a mobilização, o engajamento e a participação de todos os atores sociais em todas as fases dos processos deliberativos e de implementação, levando em conta os custos e benefícios para cada um dos agentes - sendo todos igualmente reconhecidos como cidadãos com direito a voz e veto/ voto (Matos, 2011, p. 45).

Insipirada pelas abordagens de Jaramillo Lopes e de Matos, Marina Koçouski (2013, p. 54) desenvolve o seguinte conceito:

Comunicação pública é uma estratégia ou ação comunicativa que acontece quando o olhar é direcionado ao interesse público, a partir da responsabilidade que 0 agente tem (ou assume) de reconhecer e atender o direito dos cidadãos à informação e participação em assuntos relevantes à condição humana ou vida em sociedade. Ela tem como objetivos promover a cidadania e mobilizar o debate de questões afeitas à coletividade, buscando alcançar, em estágios mais avançados, negociações e consensos.

A expressão "comunicação pública" seria assim utilizada para caracterizar um tipo específico de interlocução pautada na troca argumentativa reflexiva e recíproca que configura uma esfera pública (Koçouski, 2013). Esse entendimento habermasiano do processo comunicativo seria apenas uma parte do conceito de comunicação pública, que abrange, entre outros, uma ideia vinculada a princípios como visibilidade, inclusão, accountability e participação nos âmbitos estatal, político, organizacional e midiático.

No modelo de democracia deliberativa construído por Habermas valoriza-se o uso da linguagem voltado para a busca de um entendimento que seja livre de coerções e violências de toda sorte (racionalidade comunicativa), fundado na igualdade entre parceiros de interlocução que se atribuem reciprocamente o status de moralmente dignos de serem ouvidos e considerados em debates sobre leis e questões de interesse coletivo. A ética do discurso visa à ampliação dos horizontes éticos individuais (e não à sua supressão, como apontam muitos dos críticos de Habermas), tendo em vista a consideração de questões que dizem respeito ao que é bom para todos (ponto de vista moral) ${ }^{5}$. Para tanto, faz-se necessário encontrar princípios normativos gerais que possam, ao nortear discussões e diálogos, conciliar interesses e necessidades particulares - os quais emergem em esferas públicas parciais de interação de grupos e indivíduos - com preocupações inerentes a todos aqueles que integram uma sociedade complexa, pluralista e diferenciada (Habermas, 1997).

Mas, para desenvolver sua abordagem, esse autor teve que explicar como indivíduos e grupos, partindo dos princípios éticos ligados a seu autoentendimento e a concepções de bem-viver, podem se engajar em debates para entender e/ou solucionar questões e problemas que abrangem um horizonte de interesse coletivamente partilhado. Essa tensão entre as concepções e demandas subjetivas e particulares e a necessidade de uma generalização negociada de interesses nos faz refletir sobre as tensões que perpassam a constituição do sujeito na teoria de Habermas: de um lado, ele deve buscar sua emancipação e autonomia através da prática do discurso e da justificação pública e, ao fazer isso, ele passa a contribuir para o progresso moral coletivo. Entretanto, de outro lado, críticos de Habermas apontam que a busca da autonomia política via justificação pública nos leva a pressupor a existência de atores moral e linguisticamente competentes sem nos revelar 0 delicado e demorado processo de desenvolvimento de habilidades comunicativas, expressivas e cognitivas que leva o sujeito

5 De acordo com Habermas, "quando se trata de examinar o que é bom para todos, sem excluir ninguém, é preciso considerar o ponto de vista moral. Amplia-se 0 horizonte de interpretação de modo que ele se funde aos horizontes de outras pessoas" (2004, p.314). 
a posicionar-se diante de outros, a elaborar e proferir argumentos com segurança e desenvoltura, a justificar e defender tais argumentos quando questionado (Marques, 2013). Além disso, as estruturas institucionais, políticas e culturais, que deveriam oferecer oportunidades de desenvolvimento e aprimoramento dessas habilidades são perpassadas por assimetrias de poder e coerções pouco tematizadas por Habermas (Freitag, 1992; Kohn, 2000).

É sob esse ângulo que desejo aqui destacar que uma perspectiva de comunicação pública que se configura em torno da teoria da ação comunicativa acaba por apresentar as mesmas fragilidades e os mesmos pontos polêmicos já identificados nos trabalhos de Habermas. Entre esses últimos, podemos destacar as mesmas críticas já endereçadas a Habermas nos anos 1990 e 2000: a) a paridade requer a eliminação de desigualdades e de relações de poder e dominação; b) Habermas falha em examinar outras esferas públicas não-liberais e não-burguesas, refletindo pouco acerca de distinções de gênero, etnia e classe; c) há um acesso desigual a meios materiais de participação; assimetrias comunicativas e de poder: mesmo com uma chance igual de falar, nem todo falante estará apto a influenciar a direção da deliberação em seu favor; e) é preciso incorporar o interesse privado ao debate, uma vez que sua anulação em prol de um "nós" ou do interesse coletivo, impede que os participantes possam esclarecer seus interesses etc.

Uma perspectiva como essa presente no modelo deliberativo deveria levar em conta que qualquer forma de solução para problemas morais que coloca "entre parêntesis" o fato de que a competência linguística é desigualmente distribuída está privilegiando a reprodução de desigualdades sociais e políticas. Enfatizar o modo argumentativo e discursivo de busca de solução e/ou melhor entendimento de problemas coletivos significaria, para vários críticos de Habermas, desprezar outras formas de expressão e de uso de competências linguísticas, além de desconsiderar o modo como a opressão, o poder e a desigualdade operam na dinâmica de discussão.

A ênfase no discurso esconde o fato de que mesmo a competência linguística é distribuída hierarquicamente/desigualmente e está implicada na reprodução de exclusões. Os participantes não usam as mesmas expressões linguísticas e da mesma forma. Se a racionalidade está no uso que os sujeitos fazem da linguagem, então não existe uma só forma de racionalidade, nem uma só forma de linguagem. E todas elas têm relação intrínseca com o poder (Kohn, 2000, p. 408).

Brandão (2009, p. 31), ao assumir uma perspectiva crítica com relação à abordagem habermasiana da comunicação pública, assinala que devemos ter em mente as propostas de Nancy Fraser e Iris Young, que se dedicam a explorar o modo como a voz dos cidadãos se configura como palavra/discurso nas esferas públicas democráticas, bem como as desigualdades e assimetrias implicadas nesse processo.

De acordo com Young (2001), os princípios propostos por Habermas deixam de fora aqueles que não possuem a educação ou o vocabulário exigido para a argumentação abstrata, sendo necessário conceder-lhes formas alternativas e culturalmente situadas de expressão. A capacidade de argumentação não se encontra distribuída de modo uniforme por toda gente. Sob esse aspecto, ainda que a ética do discurso e a formação do sujeito autônomo e reflexivo sejam abordagens promissoras que Habermas traz para a teoria democrática, ele não problematiza com profundidade o processo de transformação de um sujeito em interlocutor. Dito de outro modo, se para ele a constituição de uma sociedade democrática e plural (que saiba solucionar coletivamente e racionalmente seus problemas de ordem moral através do discurso) depende do desenvolvimento das capacidades ou competências comunicativas dos indivíduos, seria necessário explicitar o processo de formação do "eu discursivamente competente" do ponto de vista cognitivo, moral, linguístico e motivacional (Marques, 2013). 
0 fato de esses constrangimentos serem capazes de impedir que as pessoas se tornem interlocutores em pé de igualdade deriva não apenas da dependência econômica e da dominação política, mas também da "internalização do direito que se tem de falar ou de não falar, da desvalorização do estilo de discurso de alguns indivíduos e da elevação de outros" (Young, 2001, p. 370).

Associada à desvalorização de estilos discursivos está a demanda de inclusão de reivindicações de grupos sociais que habitualmente não têm visibilidade e nem acesso à ordem de discurso vigente. Matos (2011, p. 41) sustenta que

o crescente envolvimento de novos atores na esfera pública contribui para a emergência de um novo conceito de comunicação pública que, enquanto configuradora de espaços de debate, negociações e tomada de decisões relativas à vida pública, passa a considerar as demandas de segmentos sociais marginalizados.

Sob essa perspectiva, a comunicação pública "deve incluir, necessariamente, todos os atores sociaisque integrama esfera pública para debater e formular propostas de ações ou de políticas que beneficiem toda a sociedade" (Matos, 2011, p. 45). Entretanto, é importante nos indagarmos acerca da natureza dessa inclusão, uma vez que, no discurso democrático participativo, todos parecem estar incluídos a priori e, no discurso deliberativo, a inclusão via uso racional da linguagem nem sempre considera modos de expressão particulares, impondo um tipo de "modelo" adequado de enunciação que acaba por continuar silenciando falas que destoam daquilo que pode ser considerado como "argumento potencialmente convincente e legítimo".

Assim, pode-se ganhar voz e não falar, ao mesmo tempo em que se pode falar a partir de um modelo discursivo silenciador da própria voz - um modelo que confere ao cidadão a impressão de que enuncia demandas próprias quando, na verdade, reproduz enunciados maquinados por dispositivos de controle.

0 ideal normativo da ética do discurso (que parece pautar essa concepção de comunicação pública) possui muitos limites já apontados pelos críticos de Habermas (e acima mencionados), sobretudo quando se trata de salientar seu tratamento restrito acerca do difícil exercício de "se apresentar" e de "aparecer diante do outro" não só como sujeito de fala, mas como efetivo interlocutor. Tendo essas restrições em mente podemos ainda pensar em uma definição de comunicação pública que tenha como fundamento os princípios democráticos presentes na teoria da ação comunicativa?

\section{AUTONOMIA POLITIICA E PARTICIPAÇÃO}

Matos (2009, p. 53), ao construir um conceito de comunicação pública inspirado no projeto habermasiano de democracia deliberativa, nos alerta sobre uma possível dimensão pouco explorada pelo autor: o processo complexo e de longo prazo que envolve a constituição dos indivíduos como sujeitos políticos, como cidadãos "capazes de reconhecerem-se como participantes sociais, de elaborar uma posição própria e expressar-se de forma a valorizar e justificar a sua posição (e a de seu grupo de referência)".

O que está em causa aqui é a autorrealização dos indivíduos como sujeitos capazes de serem reconhecidos como parceiros de interlocução e capazes de se autorreconhecerem como agentes autônomos capazes de formular, expressar, fundamentar, justificar e rever seus argumentos em uma dinâmica discursiva concreta. Se a dimensão da autonomia política não se desenvolve, dificilmente os indivíduos conseguem se integrar a processos e práticas de comunicação pública ${ }^{6}$. Como

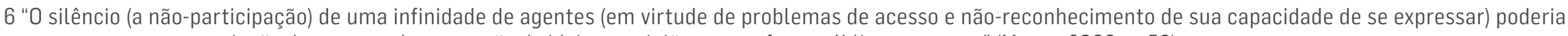
ocorrer mesmo com a criação de espaços de expressão de ideias e opiniões nas esferas públicas externas" (Matos, 2009, p. 53). 
salienta Matos (2009, p. 53), "um cidadão que não acredita ter direito a se expressar, que não valoriza o que tem a dizer e que não se sente capaz de comunicar isso adequadamente aos outros dificilmente terá condições de integrar a rede social da comunicação pública" (2009, p.53).

Novelli (2011, p. 248-249) também destaca a importância de compreendermos o modo como a autonomia política se vincula à comunicação pública, uma vez que sua interseção ocorre nas práticas participativas de envolvimento dos cidadãos em processos deliberativos e de decisão:

Sem canais adequados de comunicação, a participação política fica comprometida ou até mesmo é suprimida do processo político. Dessa forma, a comunicação como mecanismo que viabiliza a troca de informações e fomenta a participação social na atividade política torna-se elemento constitutivo do próprio processo político.

A construção da autonomia política requer que os sujeitos desenvolvam suas capacidades e habilidades de negociar e dialogar com os outros, ainda que não concordem com seus pares. Sob esse aspecto, a ação comunicativa privilegia um tipo de racionalidade que usa a linguagem para a busca do mútuo entendimento. A racionalidade não é algo inerente aos sujeitos, mas uma forma de usar a linguagem com a intenção de justificar pontos de vista e revisá-los diante de críticas alheias. Assim, o enfoque da teoria habermasiana se encontra na capacidade de formular e oferecer razões, deixando de lado as dimensões que tornam um indivíduo apto a produzir e trocar razões (as condições de constituição do sujeito político). Por isso a prática racional não deve ser percebida apenas como capacidade de oferecer e trocar razões tendo em vista o entendimento, mas sobretudo como uma prática interacional que envolve situações, relações e interfaces que podem ou não permitir que os sujeitos alcancem autonomia e autorrealização. Como afirma Matos (2011, p. 46), a dimensão comunicativa e autônoma das práticas dos atores públicos

está ligada à sua capacidade de autodefinição, de explicitação de seus objetivos, de justificação pública de suas ações e de desenvolvimento de mecanismos capazes de implicar outros setores e atores políticos e sociais em seus projetos e ações; a identidade e legitimidade de um ator público estão diretamente vinculadas às articulações comunicativas que ele estabelece com seu entorno.

A autonomia, ao depender da igualdade no sentido do reconhecimento recíproco dos sujeitos interlocutores, implica a adoção de uma atitude reflexiva em relação às próprias necessidades e desejos que não se restringe a um exercício interno, mas que só se concretiza em processos de trocas de razões em que os indivíduos devem: a) expressar publicamente suas necessidades aos outros; b) elaborar justificativas aceitáveis para suas próprias ações cotidianas; e c) reconhecer seus interlocutores como dignos de valorização e consideração (Cooke,1999, p. 26).

Não podemos deixar de salientar que a conquista da autonomia política, em seu viés relacional, depende também de componentes externas aos sujeitos, ou seja, de dimensões comunicativas, sociais e institucionais que, consideradas as assimetrias de poder e de discurso, lhes permitam participar da vida pública, sendo respeitados, ouvidos e considerados. Além disso, a participação de todos os interessados em debates referentes a questões coletivas deve ser objeto de constante reflexão, segundo Matos (2009, p. 56):

Se todos os agentes participam do debate das questões de interesse e utilidade comum, se essa participação é possível graças à existência de uma infraestrutura que materializa a esfera pública, se eles se sentem aptos e motivados a participar graças à cultura de valorização de seu papel social, se os critérios de instituição e processo do debate são claros e equitativos, então será possível preencher os requisitos mínimos para o reconhecimento da comunicação pública. 
Resta-nos saber não só que tipo de configuração dialógica pode permitir processos participativos de configuração de redes de esferas públicas, mas também quais sujeitos autônomos tecem suas demandas combinando dissenso/polêmica, dramatização e argumentação.

Não raro é possível notar que os textos que tratam da comunicação pública apreendem em suas considerações apenas a dimensão positiva que se delineia a partir de uma perspectiva dialógica, desconsiderando algumas armadilhas retóricas e até mesmo ideológicas. Fóruns de diálogo têm sido criados em contextos cívicos e organizacionais construindo regras e princípios para seu funcionamento inclusivo, paritário e reflexivo. Contudo, observamos que a emergência efetiva de discursos (e de interlocutores) ainda enfrenta problemas ligados a assimetrias de poder e à desvalorização de pontos de vista e/ou daqueles que os proferem. Muitos desenhos participativos e dialógicos em contextos institucionais reduzem a concepção de "voz" (ou de tomar a palavra) a meramente ter algo a dizer, em vez de observar a construção social do que há para ser dito, de quem deve dizê-lo e como, além da possibilidade de escuta recíproca.

A menção às relações de poder e às assimetrias comunicativas em situação de diálogo nos conduz a afirmar que não se pode tecer uma análise das trocas comunicativas e dialógicas em contextos institucionais sem levar em consideração que grande parte delas é marcada pela hostilidade, pela desvalorização dos interlocutores e seus argumentos, pelas assimetrias de status entre os participantes e, sobretudo, pela não-tematização de injustiças referentes ao próprio reconhecimento dos parceiros como moralmente dignos de serem vistos como interlocutores, como "pares". Sob esse aspecto, consideramos necessário examinar como as interações dialógicas dão a ver a criação de um espaço polêmico e dissensual no qual as diferenças podem aparecer e traçar caminhos de negociação e resistência (Marques; Mafra, 2013, 2014).

Acredito que a constituição do ator social como interlocutor deve considerar as seguintes dinâmicas: a) cada ator deve ver-se como sujeito de palavra e não só de voz; b) cada ator deve construir sua autonomia política, isto é, suas habilidades de elaborar argumentos e torná-los inteligíveis através da explicitação do mundo no qual eles fazem sentido e, com isso, despertam empatia; c) cada ator deve desidentificar-se com nomes que lhes foram atribuídos de maneira hierárquica, ou seja, deve buscar existir na conexão e desconexão de vários nomes, habilidades e discursos (Marques; Mafra, 2014).

A constituição de interlocutores ocorre simultaneamente à construção de cenas discursivas e performáticas nas quais estão em jogo a formulação, apresentação e justificação de demandas. Tais cenas são frequentemente marcadas pela visibilidade midiática e por suas lógicas operatórias.

\section{ALGUMAS BREVES CONSIDERAÇÕES SOBRE O PAPEL DA MÍDIA NO PROCESSO DE COMUNICAÇÃO PÚBLICA}

Na última seção do segundo volume da obra Teoria da ação comunicativa (1987), Habermas desenvolve o argumento de que os meios de comunicação desempenham um papel dúbio na configuração dos processos democráticos: se por um lado eles tornam públicos os discursos de atores localizados em diferentes arenas comunicativas, libertando as informações de seus contextos de origem e tornando-as acessíveis a uma vasta maioria, por outro lado os profissionais da mídia produzem um discurso alimentado por atores que lutam por acesso e por influência.

Em um texto mais recente, apesar das assimetrias de poder provocadas pela ação dos agentes midiáticos e pelo código interno de seleção e de enquadramento dos acontecimentos e da palavra pública, Habermas (2006) atribui aos meios 


\section{ANO 12 • NÚMERO $22 \cdot 1^{0}$ sem. 2015 - ORGANICOM COMUNICAÇÃO PÚBLICA E CONSTITUIÇÃO DE CENAS DE DISSENSO EM CONTEXTOS INSTITUCIONAIS}

de comunicação um lugar central no processo de organização, divulgação e espraiamento dos debates que ocorrem nas distintas esferas públicas que se configuram em âmbitos institucionais e informais. Para ele, os media e os atores sociais agem na organização e publicização de questões (compondo o que ele chama de clusters of synthesized issues) agrupando as opiniões em feixes tematicamente especificados. 0 espaço de visibilidade midiática, segundo Habermas, pode ser compreendido como um âmbito de circulação de múltiplas perspectivas e de pontos de vista cuidadosamente selecionados de modo a privilegiar alguns segmentos sociais e a salientar certos aspectos dos acontecimentos em detrimento de outros.

Contudo, os meios de comunicação podem se constituir em obstáculos para a promoção de processos democráticos quando hierarquizam e priorizam discursos, de modo a privilegiar os interesses de grupos e indivíduos. De modo geral, grande parte da sociedade civil (organizada ou não) tem sua fala excluída do espaço midiático de circulação de pontos vista e argumentos. É possível observar como isso acontece se considerarmos as seguintes características que se materializam nos diferentes textos midiáticos: a) quando o texto se refere a um determinado segmento social utilizando a terceira pessoa, sem ter a preocupação em trazer as falas dos interessados; b) quando tal segmento raramente (ou nunca) aparece como grupo ao qual os entrevistados "institucionais" se remetem (revelando que não o veem como interlocutor); c) quando há alguns sinais de que esses entrevistados acreditam que prestam contas a esse segmento social, tratando-os como objetos de um debate, ou como meros espectadores do processo decisório; e d) quando participantes desse segmento são convidados pelos meios a falar, percebe-se que raramente é o conteúdo de sua fala que interessa, mas a possibilidade de ela ilustrar um ponto de vista ou de transmitir uma "lição", geralmente ligada à superação de dificuldades pelo mérito individual.

Os veículos não são despidos de ideologias e preferências internas institucionais, assim como se posicionam politicamente diante dos acontecimentos e polêmicas atuais. Tal fato muito influencia na seletividade das fontes, na inclusão das perspectivas sociais e na escolha dos temas que irão adquirir saliência através dos enquadramentos. É preciso, portanto, não perder de vista o fato de que nem todos os segmentos sociais conseguem ter seus argumentos ou demandas de validade englobadas por um enquadramento midiático. Sobretudo quando a produção de enquadramentos está associada ao trabalho discursivo de agentes institucionais poderosos que estão continuamente engajados em disputas para atribuir significados sobre os eventos correntes.

Os meios de comunicação articulam o conteúdo discursivo que circula nos diferentes espaços de interação cotidiana, trazendo para a linha de frente os temas que os profissionais julgam relevantes, permitem a aproximação ou contraposição de perspectivas e promovem a prestação de contas entre vários interlocutores. Entretanto, nem sempre os meios de comunicação são benéficos aos processos argumentativos. Os filtros e constrangimentos por eles impostos, ao hierarquizar conteúdos e fontes, por exemplo, geram vários pontos de ruptura entre os diferentes contextos articulados em um processo deliberativo. Fluxos comunicativos que se estabelecem na periferia desse processo sob a forma de conversações informais raramente perpassam a arena dos media e, às vezes, nem mesmo demonstram ter sido gerados com a intenção de fazê-lo. Não há como desconsiderar que existe no espaço de visibilidade mediada um grande escopo de assimetrias no que tange às chances desiguais de intervenção dos diferentes públicos na produção, validação, regulação e apresentação de mensagens. 0 próprio Habermas (2006, p. 420) nos chama a atenção para o mecanismo de poder envolvido nesse processo - ainda que continue apostando na avaliação crítica promovida pelos debates que se desdobram na esfera pública:

A estratificação das oportunidades de transformar o poder em influência pública através dos canais da comunicação mediada revela, assim, uma estrutura de poder. Esse poder é coagido, contudo, pela reflexividade peculiar de uma esfera pública que permite a todos os participantes a chance de reconsiderar o que entendem por opinião pública. 
Grande parte dessas assimetrias deriva do fato de que a mídia deve ser observada, em seus processos rotineiros de funcionamento, como um sistema que abrange, entre outros itens: instituições e seus profissionais; instituições dos demais sistemas e seus agentes; audiência; ambiente sociopolítico. Assim, é preciso considerar com cuidado os seguintes elementos: a) empresas midiáticas e suas relações de interesse com grupos de poder; b) o que ganha destaque na mídia nem sempre são questões de relevância para os cidadãos; c) autopoiese e divisão de trabalho: os veículos desenvolvem recursos para sua própria manutenção, estruturando-se internamente de maneira altamente especializada; d) criação de uma cultura, ética e regras de conduta próprias (código e linguagem particulares).

É inegável o fato de que a grande mídia (meios de visibilidade massiva) inúmeras vezes não conferem visibilidade às ações de comunicação pública (sobretudo projetos de participação, engajamento cívico e aproximação entre governantes e governados) planejadas nos espaços do legislativo e das instâncias políticas administrativas. Ao lado da dificuldade de publicizar projetos e iniciativas de criação de espaços públicos híbridos, temos também o fato de que o sistema midiático opera através da seleção e edição de acontecimentos, construindo enquadramentos e uma versão específica (e ideologicamente ancorada) para os fatos (Marques, 2008). A esfera de visibilidade edita debates que existem fora dela, remetendo-os à esfera pública sob a forma de tema para debate ou para a formação da opinião, estabelecendo e alterando entendimentos.

Aos profissionais dos media cabe um grande controle da comunicação produzida: gerenciam as redes centralizadas de informações, selecionam as matérias tematizadas, os conteúdos produzidos e administram o acesso aos meios. A informação política fica em segundo plano e sucumbe ao entretenimento: aligeira-se, abrevia-se, dramatiza-se para se tornar diversão. Se, de um lado, os meios de comunicação conferem visibilidade aos discursos de atores localizados em diferentes arenas comunicativas, de outro lado, "os profissionais da mídia produzem um discurso de elite, alimentado por atores que disputam entre si por acesso e influência" (Habermas, 2006, p. 417).

Visões de uma mídia mais deliberativa incluem o jornalismo público ou cívico - rede de profissionais e educadores interessados em explorar a relação entre jornalismo e democracia (Gastil, 2008, p. 67). 0 jornalismo produzido nos moldes colaborativos estabelece uma conexão com as práticas dos meios de comunicação de massa e as redes informais de amigos, colegas e membros de comunidades. Ele explora o potencial dos cidadãos para distribuir e analisar informalmente suas próprias notícias fora do amplo sistema da mídia. Ainda que sejam identificadas diferentes formas de atuação dos veículos, todas elas apresentam lógicas assimétricas em maior ou menor medida. Cabe-nos, contudo, sempre ter em mente que a mídia enquadra as questões sobre as quais pensamos e o modo como pensamos sobre elas: por isso, acima de tudo, ela deve atuar como instituição comprometida com práticas democráticas, como ator do debate e como fórum para o debate e para a comunicação pública.

\section{CONSIDERAÇÕES FINAIS}

Habermas (2004) afirma que dedicou toda a sua trajetória acadêmica e intelectual A encontrar um modelo democrático pautado em procedimentos capazes de conduzir trocas discursivas conduzidas por sujeitos cooperativamente motivados a encontrar soluções justas para problemas morais. Sua busca se concentrava em descobrir como fazer com que diferentes grupos e indivíduos - os quais sustentam diferentes princípios éticos ligados a seu autoentendimento e concepções de bemviver - se engagem em debates públicos e se coloquem de acordo a respeito do que é considerado justo e bom para todos.

Certamente não basta estabelecer um diálogo ou debate entre sujeitos radicalmente distintos. Seria preciso informar as regras de condução dessas interações discursivas de modo a preservar interesses individuais e, ao mesmo tempo, 
estimular a elaboração de interesses coletivos. Assim, a ética do discurso (ou da discussão), tal como elaborada por Habermas, baseia-se na tentativa de apontar um modo reflexivo de comunicação intersubjetiva para a solução de conflitos e impasses normativos de fundo moral.

Se considerarmos uma definição de comunicação pública pautada pela troca argumentativa paritária e pela justificação recíproca entre diferentes instâncias, atores e instituições, como conceber cenas de dissenso que, apesar de serem perpassadas por coerções e assimetrias, produzem espaços enunciativos para a construção e o exercício da autonomia política? Como lidar com conflitos que exigem o deslocamento de posições egocentradas para assumir a perspectiva dos outros a fim de entender o que é por eles considerado injusto? Uma das principais exigências para se conceber a comunicação pública a partir dos conceitos presentes em Habermas é a prática de assumir temporariamente o lugar do outro buscando entender suas demandas, interesses e sentimentos a partir de uma identificação baseada na empatia e na solidariedade. E é justamente por isso que argumento que esse é o ponto mais forte e, ao mesmo tempo, mais frágil de sua teoria, pois esta não nos oferece muitas pistas para solucionar o que considero ser um dos maiores dilemas de sua proposição: como a ética do discurso e a busca de um ponto de vista moral pode alimentar "uma razão que una sem apagar a separação, que ligue sem negar as diferenças, que indique o comum e o que é compartilhado entre estranhos, sem privar o outro da condição de outro"? (Habermas, 2001).

\section{REFERÊNCIAS}

BRANDÃO, Elizabeth Pazito. Conceito de Comunicação pública. In: DUARTE, Jorge (Org.). Comunicação pública. 2. ed. São Paulo: Atlas, 2009. p. 1-33.

BUENO, Wilson da Costa. A política de comunicação como processo de legitimação da comunicação pública no Brasil. In: MARQUES, Ângela; OLIVEIRA, Ivone de Lourdes (Org.). Comunicação organizacional: dimensões epistemológicas e discursivas. Belo Horizonte: Fafich/UFMG, 2015. p. 228-239.

COOKE, Maeve. A space of one's own: autonomy, privacy, liberty. Philosophy \& Social Criticism, v. 25, n. 1, p. 23-53, 1999

DUARTE, Jorge (Org.). Comunicação pública: estado, mercado, sociedade e interesse público. São Paulo: Atlas, 2009.

Sobre a emergência do(s) conceito(s) de comunicação pública. In: KUNSCH, Margarida M. Krohling (Org.). Comunicação pública, sociedade e cidadania. Difusão, 2011. p. 121-134.

FREITAG, Barbara. Itinerários de Antígona: a questão da moralidade. Campinas, SP: Papirus, 1992.

GASTIL, John. Mediated deliberation and public opinion. In: GASTIL, John. Political communication and deliberation. London: Sage Publication, 2008. p. 43-76.

HABERMAS, Jürgen. Direito e democracia: entre facticidade e validade. Rio de Janeiro: Tempo Brasileiro, 1997. A Escola de Frankfurt, Folha de S.Paulo, Caderno Mais!, 22/07/2001. 
Political communication in media society: does democracy still enjoy an epistemic dimension? The impact of normative theory on empirical research. Communication Theory, v. 16, p. 411-426, 2006.

JARAMILLO LÓPEZ, Juan Camilo. Advocacy: uma estratégia de comunicação pública. In: DUARTE, Jorge (Org.). Comunicação pública: estado, mercado, sociedade e interesse público. 2. ed. São Paulo: Atlas, 2009. p. 61-80.

KOÇOUSKI, Marina. Comunicação pública: construindo um conceito. In: MATOS, Heloiza (Org.). Comunicação pública: interlocuções, interlocutores e perspectivas. São Paulo: ECA-USP, 2013. p. 41-58.

$\mathrm{KOHN}$, Margareth. Language, power, and persuasion: toward a critique of deliberative democracy. Constellations, v. 7, n. 3 , p.408-429, 2000.

KUNSCH, Margarida M. Krohling (Org.). Comunicação pública, sociedade e cidadania. São Caetano do Sul, SP: Difusão, 2011.

KUNSCH, Margarida M. Krohling. Introdução: comunicação pública a serviço da sociedade e do cidadão. In: KUNSCH, Margarida M. Krohling (Org.). Comunicação pública, sociedade e cidadania. São Caetano do Sul, SP: Difusão, 2011. p.13-19.

Comunicação pública: direitos de cidadania, fundamentos e práticas. In: MATOS, Heloiza. (Org.). Comunicação pública: interlocuções, interlocutores e perspectivas. São Paulo: ECA-USP, 2013. p.3-14.

MARQUES, Ângela. Os meios de comunicação na esfera pública: novas perspectivas para as articulações entre diferentes arenas e atores, Líbero, n. 21, p. 23-36, 2008.

. A ética do discurso e a formação do sujeito político em Habermas. Cadernos da Escola do Legislativo, v. 15, p. 3-25, 2013.

MARQUES, Ângela; MAFRA, Rennan. Diálogo no contexto organizacional e lugares de estratégia, argumentação e resistência. Organicom - Revista Brasileira de Comunicação Organizacional e Relações Públicas, n. 18, p. 72-84, 2013.

0 diálogo, o acontecimento e a criação de cenas de dissenso em contextos organizacionais. Dispositiva - Revista do Programa de Pós-Graduação em Comunicação Social da Faculdade de Comunicação e Artes da PUC-Minas, v. 2, p. 2-20, 2014.

MATOS, Heloiza. Comunicação política e comunicação pública. Organicom - Revista Brasileira de Comunicação Organizacional e Relações Públicas, São Paulo, ECA-USP, n. 4, p. 59-73, 2006.

A comunicação pública na perspectiva da teoria do reconhecimento. In: KUNSCH, Margarida M. Krohling. (Org.). Comunicação pública, sociedade e cidadania. São Caetano do Sul, SP: Difusão, 2011. p. 39-59.

Comunicação pública, esfera pública e capital social. In: DUARTE, Jorge (Org.). Comunicação pública: estado, mercado, sociedade e interesse público. São Paulo: Atlas, 2009. p. 47-58.

Comunicação pública, democracia e cidadania: o caso do Legislativo. In: CONGRESSO BRASILEIRO DE CIÊNCIAS DA COMUNICAÇÃO, XXI, Intercom, Rio de Janeiro, 1999. Disponível em: <http://www.fafich.ufmg.br/ larp/intercom99/matos. htm>. Acesso em: 28 jun. 2006. 
MATOS, Heloiza; GIL, Patrícia. Alternativas ao conceito e à prática da comunicação pública. Revista Eptic On-line, v. 15, n. 2 , p. 12-27, 2013a.

Quem é o cidadão na comunicação pública? In: MATOS, Heloiza (Org.). Comunicação pública: interlocuções, interlocutores e perspectivas. São Paulo: ECA-USP, 2013b. p. 89-106.

NOVELLI, Ana Lucia Romero. As sondagens de opinião como mecanismo de participação da sociedade. In: MATOS, Heloiza (Org.). Comunicação pública: interlocuções, interlocutores e perspectivas. São Paulo: ECA-USP, 2013. p. 243-258.

OLIVEIRA, Maria José da Costa. Comunicação organizacional e comunicação pública. In: MATOS, Heloiza (Org.). Comunicação pública: interlocuções, interlocutores e perspectivas. São Paulo: ECA-USP, 2013. p.15-28.

ROLANDO, Stefano. A dinâmica evolutiva da comunicação pública. In KUNSCH, Margarida M. Krohling (Org.). Comunicação pública, sociedade e cidadania. São Caetano do Sul, SP: Difusão, 2011. p. 23-38.

YOUNG, Iris. Comunicação e o outro: além da democracia deliberativa. In: SOUZA, Jessé. Democracia hoje: novos desafios para a teoria democrática contemporânea. Brasília: Editora da UnB, 2001. p. 365-386.

ZÉMOR, Pierre. La communication publique. Paris: PUF, 1995.

Artigo recebido em 16.03.2015 e aprovado em 01.06.2015. 